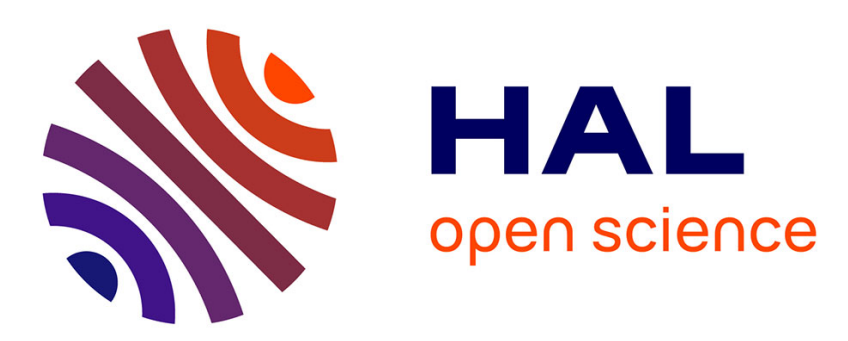

\title{
Influence of the strategies and biomechanical parameters on the capacity to handle balance perturbation: a numerical assessment
}

Pascal Vallee, Thomas Robert

\section{- To cite this version:}

Pascal Vallee, Thomas Robert. Influence of the strategies and biomechanical parameters on the capacity to handle balance perturbation: a numerical assessment. 40ème congrès de la Société de Biomécanique, Oct 2015, PARIS, France. pp. 2074-2075, 10.1080/10255842.2015.1069613 . hal01844856

\section{HAL Id: hal-01844856 \\ https://hal.science/hal-01844856}

Submitted on 19 Jul 2018

HAL is a multi-disciplinary open access archive for the deposit and dissemination of scientific research documents, whether they are published or not. The documents may come from teaching and research institutions in France or abroad, or from public or private research centers.
L'archive ouverte pluridisciplinaire HAL, est destinée au dépôt et à la diffusion de documents scientifiques de niveau recherche, publiés ou non, émanant des établissements d'enseignement et de recherche français ou étrangers, des laboratoires publics ou privés. 


\title{
Influence of the strategies and biomechanical parameters on the capacity to handle balance perturbation: a numerical assessment
}

\author{
P. Vallée and T. Robert ${ }^{\mathrm{a} *}$ \\ ${ }^{a}$ Université de Lyon F-69622, IFSTTAR, UMR_T9406, LBMC, Université Lyon1, France
}

Keywords: Balance; fall; strategies; ageing

\section{Introduction}

Fall is a major issue especially in the communitydwelling elderly population. Consequences can be extremely severe (fractures or even death) and lead to a loss of autonomy (World Health Organization, 2008). Identifying balance recovery (BR) parameters which strongly influence the success of BR process would be a very interesting track in order to train elderly on their identified physical weaknesses and consequently improve their ability to restore their balance.

BR process has been primarily investigated using an experimental approach. It allowed, for example, to define the BR characteristics such as the step length, ageing effect, timing, etc., for different population and experimental conditions (Hsiao-Wecksler and Robinovitch, 2007; McIlroy and Maki, 1996; Wojcik et al., 1999). However, it is extremely complex to experimentally manipulate the different neurological or biomechanical parameters influencing the BR. As such, there still is a lack of knowledge about their role and influence on the BR process and on the outcome of a given perturbation.

To fill this gap, there is a need of a BR model that: 1/ includes several BR strategies, in particular the change of support type of strategy (e.g. protective steps); $2 /$ describes the use of these strategies by parameters that are linked to neurological and biomechanical factors; $3 /$ is able to predict the outcome of a perturbation; $4 /$ is validated against human experimental data.

We recently proposed such a model and two sets of parameters representing young and elderly population group. This model matched experimental observations about the maximal release angle that can be handled using the fixed support strategies and a protective step (Robert and Vallée, 2014; Vallée et al., 2015).

Through this paper we propose to use this model to investigate the influence of the parameters describing the recovery actions on the maximal initial release angle that can be handled. The analysis will be performed at the level of the BR strategies (ankle, hip and protective stepping) and, through a sensitivity analysis, at the level of the neurological (timings) and biomechanical parameters (strength, ability to step, BoS limits) describing the use of these strategies. .For concision, these analyses will only be presented for the set of parameters representing the elderly population.

\section{Methods}

\subsection{Model, recovery reactions and BR condition}

The human body is represented as an Inverted Pendulum (IP) mounted on a massless foot-like Base of Support (BoS), with a concentered mass at the Center of Mass (CoM) and with a flywheel (FW) centered at the CoM.The three main BR strategies are thus represented and supposed to be used at their maximum: 1/ After a reaction time (RT) the Center of Pressure $(\mathrm{CoP})$ is instantaneously shifted toward the edge of the BoS (ankle strategy); 2/ Also after the RT the FW is launched following a bang-bang acceleration profile constrained by its maximal torque $\left(\mathrm{T}_{\max }\right)$ and its maximal angle of rotation $\left(\alpha_{\max }\right)$. This profile represent the segments' angular momentum effects (hip strategy); 3/ After an additional delay from the RT called Step Preparation Time (SPT), a protective step can be triggered. It represents a BoS extension which is bounded by the swing foot maximal acceleration $\left(A_{\max }\right)$ and, if reached, by its maximal final position $\left(\mathrm{L}_{\text {step }}\right)$. The parameters describing the use of these strategies for the elderly population group are given in Table 1.

In this study we foccus on tether-release perturbations: the model is released from an initial forward leaning posture. The BR threshold is the maximal release angle from which the model could restore its balance.

\subsection{Parameters assessment}

Firstly we determine the BR threshold for different combinations of the three recovery strategies (ankle, hip and protective stepping strategy can be cancelled by setting the Functional $\mathrm{BoS}, \mathrm{T}_{\max }$ or $\mathrm{L}_{\text {step }}$ to zero, respectively). 
Then we performed a sensitivity analysis on the BR parameters. Each parameter is varied from $50 \%$ to $150 \%$ of its initial value and the obtained thresholds $(\theta)$ are compared to the reference threshold $\theta_{\text {ref }}$ A linear regression is then fitted between the percentages of variation of the studied parameter and the induced percentages of variation of $\theta$. The slopes (K) represent the influence of each parameter on the BR threshold.

\begin{tabular}{llll}
\cline { 2 - 4 } & $\begin{array}{l}\text { Reference } \\
\text { value }\end{array}$ & $\mathrm{R}^{2}$ & $\mathrm{~K}$ \\
\hline $\mathrm{RT}(\mathrm{ms})$ & 80 & 0.99 & -0.26 \\
\hline $\mathrm{SPT}(\mathrm{ms})$ & 180 & 0.98 & -0.52 \\
$\mathrm{~A}_{\max }\left(\mathrm{m} . \mathrm{s}^{-2}\right)$ & 145 & 0.98 & 0.28 \\
$\mathrm{~L}_{\text {step }}(\%$ body height) & 55 & 0.99 & 0.74 \\
\hline Functional BoS (\% BoS) & 42 & 0.99 & 0.15 \\
\hline $\mathrm{T}_{\max }(\mathrm{N} . \mathrm{m})$ & 150 & 0.99 & 0.15 \\
$\alpha_{\max }(\mathrm{rad})$ & $\pi / 4$ & 0.86 & 0 \\
\hline
\end{tabular}

Table 1: Elderly parameter set from Vallée et al. 2015. Coefficient of determination is displayed as $\mathrm{R}^{2}$ value and the influence on the BR threshold is represented as the $\mathrm{K}$ value.

\section{Results and discussion}

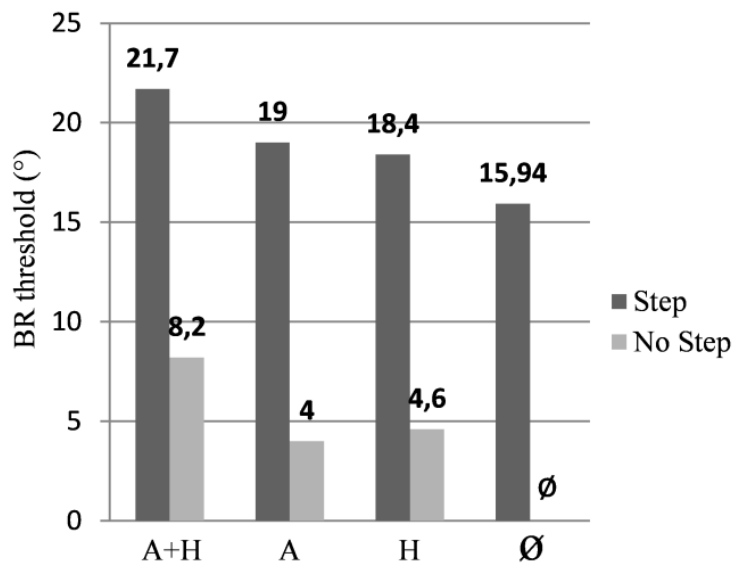

Figure 1: One step BR threshold angle according to strategies enabling (A: Ankle; H: Hip; $\varnothing$ : No strategy)

The stepping strategy is from far the most influent strategy (see Figure 1). The influence of the ankle and the hip strategy appears to be slightly equivalent.

The sensitivity analysis confirmed this first approach. Parameter variations are linearly linked to the induced variations of the $B R$ threshold (see $R^{2}$ in Table 1). The maximal step length $\left(\mathrm{L}_{\text {step }}\right)$ and the SPT are the most influent parameters with a $\mathrm{K}$ coefficient of 0.8 and -0.5 , respectively. An increase of $L_{\text {step }}$ by $10 \mathrm{~cm}$ or a decrease of SPT by $10 \mathrm{~ms}$ induces an increase of the BR threshold of $2^{\circ}$ and $0.7^{\circ}$ respectively. Other parameters as the RT, $\alpha_{\max }, \mathrm{A}_{\max }$ and functional
BoSsize have a smaller influence on the threshold evolution with a $\mathrm{K}$ value between -0.26 and 0.3 .

This model showed that the most important strategy to be able to recover a large TR perturbation is the ability to perform a recovery step. This step has to be the furthest possible but also has to be initiated as soon as possible with a reduction of the SPT corresponding to anticipatory postural adjustments (APA) needed to trigger the step. The influence of the RT is less important because its duration is already short compared to SPT (see Table 1).

\section{Conclusions}

To sum up, we propose an investigation of biomechanical parameters of a numerical model previously validated with experimental data from the literature. First results confirm that triggering a step is a very effective way to handle large perturbations (more than using fixed-support strategies). But this model also provided a quantitative evaluation of other BR parameters which cannot be investigated experimentally. Further developments have to be done in order to integrate more complex and realistic perturbations in various directions but also other BR reactions as for example grasping. Nonetheless these results highlight the importance of the protective stepping on the ability to avoid a fall and provide interesting insight into the detection and care of the person at higher risk of fall.

\section{References}

Hsiao-Wecksler, E.T., Robinovitch, S.N., 2007.The effect of step length on young and elderly women's ability to recover balance.Clin.Biomech.22, 574-80.

McIlroy, W.E., Maki, B.E., 1996. Age-related changes in compensatory stepping in response to unpredictable perturbations. J. Gerontol. A. Biol. Sci. Med. Sci. 51, M289-M296.

Robert, T., Vallée, P., 2014.Assessment of a numerical model of balance recovery by stepping.Comput.Methods

Biomech.Biomed.Engin.17 Suppl 1, 176-7.

Thelen, D.G., Wojcik, L. a, Schultz, a B., AshtonMiller, J. a, Alexander, N.B., 1997.Age differences in using a rapid step to regain balance during a forward fall. J. Gerontol. A. Biol. Sci. Med. Sci. 52, M8-13.

Vallée, P., Tisserand, R., Robert, T., 2015.Possible recovery or unavoidable fall?A model to predict the one step balance recovery threshold and its stepping characteristics. J. Biomech (submitted).

Wojcik, L. a, Thelen, D., Schultz, A., Ashton-Miller, J., Alexander, N., 1999.Age and Gender differences in single step recovery from a forward fall. $\mathrm{J}$. Gerontol. 54, 44-50.

World Health Organization, 2008. Global report on falls Prevention in older Age 